\title{
AS COMPETÊNCIAS, OS PERFIS E OS ASPECTOS SOCIAIS DO BIBLIOTECÁRIO NA EDUCAÇÃO
}

\author{
COMPETENCIES, PROFILES AND SOCIAL ASPECTS \\ OF THE LIBRARIAN IN EDUCATION \\ COMPETENCIAS, PERFILES Y ASPECTOS SOCIALES \\ DE LO BIBLIOTECARIO EN EDUCACIÓN
}

Claudio Marcondes de Castro Filho ${ }^{1}$

\section{RESUMO}

A biblioteca escolar deve ser reconhecida como um equipamento cultural, como uma instituição social, com o intuito de integrar a sociedade da informação, estabelecendo novos conceitos e se adequando às realidades sociais, culturais, educativas e tecnológicas da sociedade. Com a explosão informacional, a sociedade contemporânea necessita de profissionais bibliotecários atuando em biblioteca escolar com competências que atendam às novas demandas de produtos e serviços de informação. Sendo assim: qual é o papel e as competências desses profissionais? Estão preparados para a demanda social de nossos leitores? Assim, o objetivo deste estudo é apontar os perfis, as competências e os aspectos sociais do bibliotecário no espaço contemporâneo, tendo como escopo a biblioteca escolar. Para nossa investigação, utilizamos como método científico a pesquisa exploratória, que tem como finalidade desenvolver e elucidar conceitos e ideias e que normalmente envolvem a pesquisa bibliográfica e documental. Com relação ao bibliotecário escolar, apontamos que este deve ter como práticas de atuação: a intermediação entre a biblioteca, o leitor e o contexto, a técnica e a promoção da leitura; deve estar atento para ajudar a amenizar, a exclusão digital e a falta de acesso à informação; não deve prescindir de conjunto de atitudes, habilidades e competências que o certifiquem a trabalhar e contribuir de forma positiva; deve ser flexível, saber administrar a unidade de informação escolar, gerando recursos e serviços de informação, trabalhar com as ferramentas disponibilizadas pelas tecnologias da informação e comunicação e aproximar a comunidade escolar com o espaço da biblioteca.

PALAVRAS-ChAVE: Biblioteca escolar. Bibliotecário. Competência. Social. Tecnologias da Informação e Comunicação.

\begin{abstract}
The school library should be recognized as a cultural facility, as a social institution, in order to integrate the information society, establishing new concepts and adapting itself to the realities of the social, cultural, educational and technological society. With the information explosion, contemporary society requires librarians working in the school library with competencies that meet the new demands of information products and services. So come the questions: What are the role and skills of these professionals? Are they prepared to fulfill the social demand for our readers? The objective of this study is to point out the profiles, competencies and social aspects of the librarian in the contemporary space, with the scope of the school library. For our investigation, we use the scientific method as the exploratory research, which aims to develop and elucidate concepts and ideas which usually involve the bibliographic and documentary research. Regarding the school librarian, he should have as acting practices: the mediation between the library, the reader and the context, the technique and the promotion of reading; he should be alert to help alleviating the digital divide and the lack of access to information; he should make available a set of attitudes, skills and competencies that certify
\end{abstract}

\footnotetext{
${ }^{1}$ Possui graduação em Comunicação Social pela Faculdade Anhembi Morumbi (1989). Chefe do Departamento de Educação, Informação e Comunicação da FFCLRP/USP.São Paulo, São Paulo - Brasil. http://orcid.org/00000003-0889-4291. Email: claudiomarcondes@ffclrp.usp.br
}

Enviado em: 28/02/2016 - Aceito em: 01/05/2016.

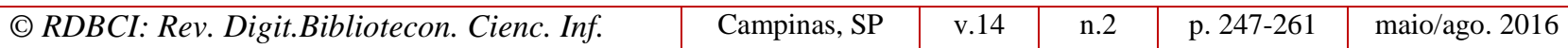


him to work and contribute in a positive way; he must be flexible and he must be able to administer the unit of school information, generating resources and information services, to work with the tools provided by information and communication technologies and to bring the school community with the library space.

KEYWORDS: Social. School library. Librarian. Competence. Technologies of Information and Communication.

\section{RESUMEN}

La biblioteca de la escuela debe ser reconocido como un centro cultural, una institución social, con el fin de integrar la sociedad de la información, el establecimiento de nuevos conceptos y la adaptación a sociedad social, cultural, educativa y tecnológica. Con la explosión de la información, la sociedad contemporánea necesita bibliotecarios que trabajan en la biblioteca con habilidades para responder a las nuevas demandas de productos y servicios de información. Así que: ¿cuál es el papel y las habilidades de estos profesionales? Ellos se preparan para la demanda social para nuestros lectores? El objetivo de este estudio es señalar los perfiles, competencias, habilidades y aspectos sociales del bibliotecario en el espacio contemporâneo. Para nuestra investigación, utilizamos el método científico como la investigación exploratoria, que tiene como objetivo desarrollar y aclarar conceptos e ideas que por lo general implican la investigación bibliográfica y documental. En cuanto el bibliotecario de la escuela, que señaló que esto debe tener como prácticas de desempeño: la mediación entre la biblioteca, el lector y el contexto, la técnica y el fomento de la lectura; debe estar alerta para ayudar a minimiza; no debe prescindir conjunto de actitudes, habilidades y competencias que certifican el trabajo y contribuyen de manera positiva; debe ser flexible, capaz de administrar la información de la escuela unitaria, la generación de recursos y servicios de información, trabajar con las herramientas proporcionadas por las tecnologías de la información y la comunicación y unir a la comunidad de la escuela con espacio de la biblioteca.

PALABRAS ClaVE: Biblioteca de la escuela. Bibliotecario. Competencia. Social. Tecnologías de Información y Comunicación.

\section{INTRODUÇÃ̃o}

Nas últimas décadas, com o advento das tecnologias de informação e comunicação, a disseminação da informação passou por transformações que geraram outras formas de divulgação da produção científica e literária. Essa mudança de paradigma tornou imprescindível a remodelação de conteúdos no processo de formação dos bibliotecários, que devem ter um "[...] papel de intelectual comprometido, com a biblioteca como instrumento de democratização, contra a miséria, a injustiça, a violência, contra tudo que restrinja a liberdade de pensamento" (CASTRILLÓN, 2004, p. 31, tradução nossa).

No entanto, para Cendón, et al. (2005), os bibliotecários passaram a se deparar com um novo contexto no mundo do trabalho, que lhes exige conhecimentos e habilidades no uso de tecnologias para organizar, processar, recuperar e disseminar informações, independentemente do suporte no qual elas estejam registradas.

Entretanto, a presença das tecnologias de informação e comunicação na escola não significa que estejam comumente integrados à biblioteca e às atividades desenvolvidas, no âmbito das várias disciplinas ministradas aos alunos. Essa situação nos leva a concordar com a afirmação de que é "[...] um grande desafio a integração de recursos eletrônicos com as 
funções tradicionais da biblioteca" (CUEVAS CERVERÓ, 2007, p. 181, tradução nossa), que exige ainda mais esforços e habilidades dos profissionais que atuam nas escolas, a fim de aproximar a biblioteca e seus leitores dessas novas ferramentas, valendo-se de suas funcionalidades para tecer uma relação mais criativa com o saber.

Para Campello (2010, p. 198), “[...] a integração e a cooperação entre bibliotecários, professores, pedagogos e toda equipe da escola torna-se imprescindível para que o bibliotecário possa ser reconhecido como catalizador/protagonista dessa colaboração". Nesse aspecto, Moraes; Valadares e Amorim (2013, p. 59) apontam que o bibliotecário exerce uma função educativa que "[...] se estende ao ensino-aprendizagem de habilidades específicas e vinculadas à pesquisa, tanto no que diz respeito ao conhecimento e busca das fontes de informações, como no que tange ao seu uso".

Autores como Fragoso (2002) e Silva, Ferreira e Scorsi (2009) retomam esses sentidos, apontando diferentes ações a serem realizadas pelos bibliotecários, como: o atendimento às necessidades dos alunos, professores e outros membros da comunidade escolar; a orientação nas consultas, leituras e utilização da biblioteca; o incentivo ao pensamento crítico e reflexivo; a disponibilização de diversos recursos e serviços; e a promoção da interação entre professores, bibliotecários e alunos.

Com a inserção das tecnologias de informação e comunicação, a biblioteca passa a ingressar a chamada sociedade da informação, pois "[...] a biblioteca escolar é para os estudantes a porta de entrada para a sociedade do conhecimento e da informação" (FUENTES ROMERO, 2006, p. 30, tradução nossa). Nessa perspectiva, o bibliotecário escolar tem a função de se adequar a essa sociedade, inserindo crianças e jovens em seu âmbito e também promovendo a chamada competência em informação (information literacy IL), que "abrange desde os processos de busca da informação para construção do conhecimento, pelas habilidades em tecnologia da informação até o aprendizado independente, por meio da interação social dos sujeitos" (FUENTES ROMERO, 2006, p. 30, tradução nossa).

A information literacy tem por objetivo "[...] formar indivíduos que aprendem por toda a vida" (QUEIROZ, 2006, p. 25), através de um processo educativo independente, crítico, ativo e investigativo. Consideramos que essas competências, em vez de se configurarem de maneira mecânica, devem auxiliar a construção de conhecimentos de forma mais ampla e criativa, colaborando para práticas de ensino-aprendizagem mais plurais, pelas quais os estudantes possam ter acesso aos livros e à leitura, à informação e à tecnologia da informação e comunicação, buscando com isso diferentes perspectivas (AMERICAN ASSOCIATION OF SCHOOL LIBRARIANS, 2007). Há quem defenda “[...] a urgente necessidade de se considerar no processo de letramento informacional, a inter-relação entre os conhecimentos e informações presentes nos portadores textuais acessados no ambiente da biblioteca escolar" (MORAES; VALADARES; AMORIM, 2013, p. 53). 
Em relação ao âmbito das bibliotecas escolares, espera-se do bibliotecário um conjunto de saberes, como suas competências e habilidades técnicas e tecnológicas que permitam auxiliar a formação de leitores e aprendizes capazes de "[...] compartilhar conhecimento e aprendizagem, tanto em situações presenciais quanto por meio do uso de tecnologia" (AMERICAN ASSOCIATION OF SCHOLL LIBRARIANS, 2007, p. 2). Interessa-nos aqui abordar esses conhecimentos esperados do bibliotecário no contexto educacional do século XXI, apontando também algumas questões referentes às bibliotecas e à sua atuação no âmbito social.

Nesse aspecto, a biblioteca escolar deve ser reconhecida como um equipamento cultural e, ainda, como uma instituição social, com intuito de integrar a sociedade da informação, estabelecendo novos conceitos e se adequando às realidades sociais, culturais, educativas e tecnológicas da sociedade. Com a explosão informacional, a sociedade contemporânea necessita de profissionais bibliotecários que atuem em biblioteca escolar com competências que possam atender às novas demandas de produtos e serviços de informação. Sendo assim: Quais são as competências desses profissionais? Estão preparados para a demanda social de nossos leitores? Tais informações são extremamente relevantes, pois o bibliotecário deve transcender os aspectos burocráticos da organização da informação e realizar ações criativas que visam a formação não somente de leitores, mas também de pesquisadores. Nesse sentido, o objetivo desse estudo é apontar o papel, o perfil e as competências do bibliotecário no campo social utilizando como escopo a biblioteca escolar.

Para nossa investigação, utilizamos a pesquisa exploratória, que tem como finalidade desenvolver e elucidar conceitos e ideias, e que normalmente envolvem a pesquisa bibliográfica e documental. Segundo Gil (1999, p. 43), este método tem como objetivo "[...] proporcionar uma visão geral, de tipo aproximativo, a cerca de determinado fato". Para Marconi e Lakatos (2006), na pesquisa bibliográfica utiliza-se documentação de natureza diversa e publicada em diferentes suportes.

\section{BIBLIOTECA ESCOLAR COMO ESPAÇO EDUCATIVO}

A biblioteca escolar demanda em sua gestão um posicionamento como lugar de disseminação cultural, de "[...] encontro de pessoas, pipocar de teclados de notebooks e dispersão de livros" (ARENA, 2009, p. 162). Um lugar de circulação de diferentes sujeitos, sentidos, serviços e recursos (incluindo os eletrônicos), não se restringindo mas devendo ir além de um apoio meramente didático-pedagógico (PERROTTI, 2006), explorando sua multiplicidade, suas várias dimensões, como as citadas por Ely (2003): social, informativa, criativa, pedagógica e recreativa; dimensões que significam as funções a serem desempenhadas pelas bibliotecas, de acordo com a International Association of School Librarianship (1993). 
Entre uma dessas diversas funções, destacamos a mediação do acervo, para que a biblioteca não seja mais um lugar de imposição de leituras, fechado para sua circulação, que impede diferentes experiências com as obras e afetando o despertar do gosto pela leitura. Consideramos que, lançando mão de uma diversidade de obras, suportes informacionais e atividades amparadas por uma nova concepção de leitura, escrita e apreensão dos sentidos, o bibliotecário, juntamente com os educadores, poderá fazer da biblioteca um lugar privilegiado para um processo de ensino-aprendizagem mais profícuo (FERRAREZI, 2010).

Atualmente atingindo um perfil almejado de biblioteca escolar, destacamos a existência do modelo hispanoamericano denominado Centro de Recursos e Aprendizagem (CRA), considerado essencial para a educação no âmbito da sociedade do conhecimento que reclama um novo padrão de biblioteca escolar (CUEVAS CERVERÓ, 2007), diferente da ideia tradicional de biblioteca como um lugar isolado da dinâmica da escola, destinado somente a organizar e conservar livros (MARZAL; CUEVAS CERVERÓ, 2007). Tal modelo não anula, mas enriquece a noção convencional ao integrar os recursos eletrônicos, a dimensão educativa, o princípio de aprendizagem autônoma e a formação ao longo da vida. Caracterizado pela existência de diversos recursos e serviços de acordo com o projeto pedagógico, no qual deverá estar incluído e não ser visto como seu complemento, o CRA:

\footnotetext{
[...] é o espaço de caráter pedagógico que contribui de maneira permanente para a inovação educativa. Reúne uma gama variada de recursos de informação em diversos suportes (bibliográficos, eletrônicos e audiovisuais, entre outros), organizando-os de acordo com os requisitos do projeto curricular de modo a tornálos disponíveis para os usuários, alunos e professores do centro, através dos seus vários serviços (MARZAL; CUEVAS CERVERÓ, 2007, p. 9, tradução nossa).
}

Assumindo a função da biblioteca escolar como um "[...] novo espaço educativo dinâmico" [...] (CUEVAS CERVERÓ, 2007, p. 178, tradução nossa), o CRA visa a formação, a informação, o entretenimento, o intercâmbio e o conhecimento. Sobre essa nova ótica, "[...] a biblioteca, para exercer a sua função, deixa de ser o acervo milenar passivo e passa a ser um serviço ativo de informação" (MILANESI, 2002, p. 77).

Ressaltamos ainda que a nova denominação de biblioteca refere-se à biblioteca escolar de sempre, porém adaptada aos novos tempos: “[...] pode-se chamar biblioteca escolar, centro de recursos, centro de recursos multimedia, centro de documentação curricular, mídiateca etc., mas sempre estamos nos referindo à mesma ideia" (FUENTES ROMERO, 2006, p. 22, tradução nossa).

Consideramos que uma biblioteca escolar mais dinâmica, formada por uma variedade de recursos movimentados por atividades educativas, lúdicas e de leitura, pode inaugurar novas maneiras de aprender, mais atraentes e polissêmicas, aproximando os sujeitos de diferentes linguagens, sentidos e também de outros sujeitos, superando práticas rígidas e desestimulantes encontradas frequentemente nas escolas. Para que haja mudanças, a biblioteca escolar precisa contar com um profissional preparado e interessado em colocá-las

\begin{tabular}{l|c|c|c|c|c} 
(C) RDBCI: Rev. Digit.Bibliotecon. Cienc. Inf. & Campinas, SP & v.14 & n.2 & p. 247-261 maio/ago. 2016
\end{tabular}


em prática, pois "[...] não basta que a biblioteca exista fisicamente para que sua identidade se consolide. São os atores (coincidentes com o processo educativo) que lhe darão sustentação" (ANTUNES, 1998, p. 177).

\section{PERFIL DO BIBLIOTECÁRIO SOCIAL E SUAS COMPETÊNCIAS}

Pensando nas questões do perfil do bibliotecário social e suas competências, destacamos que de tempos em tempos as tarefas mudam, em razão das tecnologias, dos movimentos sociais, políticos ou culturais, fazendo com que os ambientes informacionais e os próprios profissionais também tenham que se adaptar às mudanças. Nesse sentido, Souto (2003, p. 10) destaca que "[...] a tecnologia traz novas exigências quanto aos atributos dos trabalhadores, e requer destes maior preparo e educação permanente para o desempenho de funções que estão em constante mudança". Além das unidades de informação convencionais, como as bibliotecas universitárias, públicas, escolares, instituições públicas e ONGs, outros espaços se abrem para a atuação do bibliotecário, tais como cinematecas, filmotecas, videotecas, centro de documentação e pesquisa, empresas privadas, museus, livrarias e editoras, além da internet, em que destacamos a elaboração de $b \log s$, bibliotecas virtuais e a indexação de sites (CUNHA; CRIVELLARI, 2004). Observamos que, em alguns casos, suportes de informação como vídeos, CDs, blogs e bibliotecas digitais também estão inseridos nas unidades de informação que denominamos de convencionais, exigindo novas práticas por parte dos bibliotecários tanto no que diz respeito ao seu tratamento quanto à sua dinamização.

$\mathrm{Na}$ literatura científica, o bibliotecário é visto como aquele que "[...] adquire a informação, organiza, descreve, indexa, armazena, recupera e a distribui para os usuários" (TARGINO, 2000, p. 64). Para tanto, esse profissional deve apresentar em seu perfil um conjunto de atitudes, habilidades e competências que lhe permitam trabalhar e contribuir de forma positiva nos diferentes espaços em que atua. Como exemplo, citamos a necessidade de que ele seja flexível, saiba administrar unidades de informação, seja comunicativo, saiba gerir recursos e serviços informacionais e saiba lidar com as ferramentas disponibilizadas pelas tecnologias da informação e comunicação (WALTER; BAPTISTA, 2008). Além disso, Faria et al. (2005) aponta ainda outras características atribuídas a esses profissionais, que passam a ser os responsáveis pelo acervo da instituição em que atuam, por estruturarem e manterem a memória da instituição. É viável também que esse profissional possa trabalhar com os recursos humanos, dando sustentação às práticas de compartilhamento do conhecimento dentro da organização.

Chegamos, nesse momento, a um ponto importante; nas bibliotecas escolares a ação bibliotecária deve ter como foco os leitores e não o acervo. Em texto justamente intitulado $A$ poesia, Jorge Luis Borges, bibliotecário de fato e ficção, oferece um relato poético que parece comentar essa ação bibliotecária: 
Emerson disse que uma biblioteca é um gabinete mágico em que há muitos espíritos enfeitiçados. Despertam quando os chamamos; enquanto não abrimos um livro, esse livro, literalmente, geometricamente, é um volume, uma coisa entre coisas. Quando o abrimos, quando o livro dá com seu leitor, ocorre o fato estético (BORGES, 1999, p, 284).

Desse modo, o bibliotecário deve transcender os aspectos burocráticos da organização da informação, suplantando assim uma prática comum nas bibliotecas das escolas, que se refere à concentração nas atividades de ordenação das estantes e a subsequente não realização de "[...] ações criativas que visam à formação de leitores e pesquisadores" (ALMEIDA JÚNIOR; BORTOLIN, 2009, p. 205).

Os teóricos Silva, Ferreira e Scorsi $(2009$, p. 62) apontam que, a partir de uma nova perspectiva para o trabalho bibliotecário, a biblioteca escolar não precisa nem pode ser um lugar de excessiva ordenação, normatização e resguardo, mas um "[...] lugar para as escolhas de cada leitor, para as indicações deste a outro, para conversas em torno dos livros”. Sob essa ótica, o bibliotecário abre-se a novas atividades "[...] relacionadas com a promoção da leitura, atividades de extensão cultural para a comunidade, recreação, lazer, etc.” (FURTADO, 2004, p. 8), ultrapassando-se o foco apenas no empréstimo de obras e criando "[...] em torno das ações de leitura e pesquisa um clima de liberdade e ludicidade" (ALMEIDA JÚNIOR; BORTOLIN, 2009, p. 206). E, ainda, de acordo com Castro Filho e Campos (2014, p. 23), que seja

[...] um laboratório de pesquisa, que se permite que formem leitores; um centro de fazer educativo; que seja um local de comunicação e de utilização de várias fontes de informação, seja no suporte físico, impresso ou virtual; de busca de questionamentos e soluções de problemas; que precisa ser ativa; de entretenimento; e que tem como missão o desenvolvimento e a formação dos cidadãos.

Esse profissional é visto por Rigoleto e Di Giorgi (2009, p. 229) como um educador apto a "[...] despertar o interesse do leitor, multiplicar as práticas de leitura e oferecer a diversidade de material [...]". Maroto (2012, p. 133) também frisa a necessidade de que esse profissional esteja preparado para o exercício da leitura e sua difusão, o que implica que ele também seja, além de dinâmico, um leitor que goste de ler, conforme apontado por Fragoso (2002).

Discute-se atualmente a questão das competências desejadas para o bibliotecário escolar, sendo frequentes as seguintes menções: à criatividade; ao interesse; aos conhecimentos de organização de bibliotecas; à capacitação para atender as demandas dos leitores; ao conhecimento sobre a realidade da escola. Buscam-se "[...] outros espaços e outras práticas de atuação e de intermediação entre a biblioteca e o leitor; entre o leitor e o contexto; entre a técnica e a promoção da leitura" (MAROTO, 2012, p. 132). Para Perrenoud (2013, p. 27), com a evolução global da sociedade, o mundo "[...] exige que se tenham cada vez mais competências. Competências diversificadas e competências que se desenvolvam em função das tecnologias, dos modos de vida, do trabalho, etc." Para tanto, Perrenoud (2013, p. 
141) definiu algumas competências que podemos relacionar com o trabalho do bibliotecário: "[...] saber, individualmente ou em grupo, elaborar e conduzir projetos, desenvolver estratégias; saber cooperar, participar de um grupo e compartilhar uma liderança; saber gerir e dirimir conflitos; saber analisar de modo sistemático, as situações e as relações".

Para Farias e Cunha (2009, p. 32), o bibliotecário escolar tem como ações - o que consideramos como competências - quatro dimensões: a) técnica, no sentido de "[...] dominar com propriedade o campo específico de atuação", ou seja, apoderar-se do conhecimento adquirido e reconstruí-lo de acordo com os usuários; b) estética, no sentido de que o bibliotecário escolar utilize "[...] sensibilidade e criatividade [...]"; c) ética, no sentido do convívio e da realização de um bem coletivo; d) política, no significado da formação de cidadãos.

Para Castro Filho (2013, p. 21), existem: a) as "[...] competências específicas [...]", que determinam um alto grau de conhecimento, ou seja, de uso de ferramentas aplicativas à biblioteconomia; b) as "[...] competências intelectuais [...]", que estão relacionadas à gestão da informação e às tomadas de decisões; c) as "[...] competências sociais e políticas [...]", que envolvem diretamente uma determinada comunidade, como o conhecimento de grupos específicos de usuários de uma área do conhecimento; d) as “[...] competências metodológicas [...]", que fornecem suporte na utilização de fluxos de informação, como também na elaboração de políticas, normas e procedimentos.

Portanto, o trabalho nas bibliotecas escolares exige do profissional que nela atua mais do que saber organizar e classificar os materiais do acervo - exige atributos como: colaboração e parceria entre bibliotecas; cultura de captura e compartilhamento do conhecimento; trabalho em equipe incluindo profissionais de outras áreas de conhecimento; e adoção de práticas de gestão do conhecimento e de um novo estilo de gestão da biblioteca.

\section{Discussão: A BIBLIOTECA ESCOLAR E O PERFIL SOCIAL DO BIBLIOTECÁRIO}

Diante de algumas explanações teóricas sobre a biblioteca escolar e o aspecto social do bibliotecário que nela trabalha, o presente trabalho alerta para um ponto importante: a necessidade de profissionais bibliotecários que atuem na biblioteca escolar com competências que possam atender às novas demandas de produtos e serviços de informação.

Frente a estas questões, cabe aos bibliotecários que gerenciam as bibliotecas escolares: a) programar e projetar ações; b) planejar os custos de serviços e produtos; c) organizar atividades cooperativas entre os leitores; d) realizar difusão e eventos culturais, de fomento à leitura, de caráter infanto-juvenil, de capacitação dos leitores para realizar a pesquisa e o ensino (CASTRO FILHO; PACAGNELLA, 2011), ou seja: “[...] o bibliotecário 
não deve limitar-se a questões técnicas de organização do acervo; de modo que assumam uma postura reflexiva e ativa do contexto em que atuam" (BRANDÃO, 2014, p. 65).

Como bibliotecário que assume o papel de educador social, Dudziak (2007, p. 96) destaca que

[...] como agente educacional de transformação, o bibliotecário assume para si, além do papel de educador, a renovação de sua própria competência, adotando e disseminando práticas transformadoras na comunidade como: pratica o aprender a aprender; difunde e populariza a ciência; explica as implicações da tecnologia; discute a realidade social e política; alerta para a responsabilidade social e ambiental. É, antes de tudo, sua atuação como líder e cidadão que sobressai.

Nesse contexto, o bibliotecário deve estar constantemente atualizado e preparado para os desafios que a sociedade contemporânea impõe - o que contribui para o exercício da cidadania.

Outro aspecto a destacar é o papel social do bibliotecário diante da mediação da informação e da leitura, ação que pode ser realizada como abordagem educativa: “[...] nessa sociedade, o papel educativo do bibliotecário torna-se mais evidente, tendo em vista suas competências específicas para atuar como mediador de leitura" (RASTELI; CAVALCANTE, 2013, p.159). Sobre as competências, Almeida, Costa e Pinheiro (2012, p. 472) assinalam que "[...] a mediação da leitura constituiu-se um dos processos de aproximação do leitor com o texto de forma significativa, uma vez que mediar é facilitar a relação deste indivíduo com o texto, filtrando a informação antes de passá-la para o receptor".

Acreditamos que o final desta última frase deva ser matizado, lido com zelo e precaução, dado o perigo do peremptório verbo filtrar: a ação mediadora do bibliotecário deve organizar o conhecimento e a informação de modo que o usuário encontre o que necessita da maneira mais rápida e eficiente possível, sem perder tempo com dados obsoletos ou inúteis, e sem se perder na imensa massa de fontes e referências que podem naufragá-lo no atual mar digital. Organizar o conhecimento e a informação não implica fazer escolhas em nome de, nem tutelar ou dirigir o olhar do leitor, mas sim preservar sua curiosidade crítica, deixar aberto e aguçado (realmente interessado) seu espírito investigativo.

Stumpf (1987) e Oliveira (1987) destacam algumas competências que se exigem dos bibliotecários, como o exercício de funções educativas, culturais, sociais, recreativas educativas. Essas competências atuam de acordo com os planos curriculares, na formação do indivíduo, na difusão e ampliação do conhecimento, fazendo com que os processos da leitura e da pesquisa não sejam nem imposição nem obrigação, mas fonte e produto de prazer e satisfação. Portanto, o bibliotecário deve ter estima pela leitura e uma preocupação constante com sua atualização e sua capacitação a fim de aperfeiçoar suas metodologias de trabalho como educador social. 
Em se tratando de mediação, Brandão (2014, p. 71) destaca que existe outra prática importante, que é a

[...] mediação voltada à formação da cidadania, aonde o bibliotecário mobiliza os materiais do acervo, visando à formação do indivíduo para acessar e utilizar informações, tomando consciência de seus direitos e deveres, e adquirindo formação para viver em uma sociedade.

$\mathrm{Na}$ conjunção das tecnologias de informação e comunicação, o bibliotecário deve tomar consciência das mudanças ocorridas nos séculos XX e XXI, de modo a aprimorar suas competências e promover produtos e serviços que atendam às necessidades dos usuários contemporâneos. Nesse sentido, o bibliotecário precisa estar atento para amenizar a exclusão digital e a falta de acesso à informação (com ações como: instalar uma ilha de wi-fi na biblioteca; ensinar a manejar o dispositivo e as ferramentas de pesquisa próprias da internet). Ao contribuir para a inclusão digital, o bibliotecário assume uma postura política e social, sua função na sociedade brasileira.

Por fim, frisamos a importância de verificar se os cursos de formação em Biblioteconomia e Ciência da Informação estão preparando seus alunos para atuarem nas bibliotecas escolares. Julgamos que as políticas públicas e as competências essenciais desses profissionais são qualidades pertinentes e necessárias para a realização de práticas educativas e culturais.

\section{CONSIDERAÇÕES FINAIS}

Com relação às competências do bibliotecário, podemos destacar que, primeiramente, ele deve ter consciência do significado e do valor da informação na sociedade atual e, consequentemente, de seu papel social como mediador de leitura e de informação. $\mathrm{O}$ bibliotecário também precisa ser proativo, dinâmico e criativo adaptando-se às mudanças constantes que ocorrem com as tecnologias de informação e comunicação; precisa trabalhar em grupo, utilizando-se das TICs (participar de salas tutoriais, de conferências, de interação e comunicação com o usuário).

Algumas das atribuições do bibliotecário escolar são: a) ter consciência do seu papel como agente de transformação social; b) ter a informação como objeto de trabalho e pesquisa; c) elaborar e trabalhar novas metodologias de tratamento da informação; d) participar do planejamento de políticas públicas e de informação para o país; e) otimizar o uso das telecomunicações e das tecnologias de informação e comunicação; f) ser um profissional aberto e crítico, com capacidade de se adaptar às mudanças, uma vez que tanto os suportes informacionais como os canais de acesso, disseminação e transferência da informação estão constantemente em mutação. 
Assim, qual seria o momento de capacitar bibliotecários escolares no sentido de alcançar competências, de realizar ações de inclusão que articulem a biblioteca escolar, as tecnologias e o leitor? Durante a formação, a especialização, a pós-graduação? Uma configuração possível seria gerar uma política de biblioteca escolar para o Brasil como um todo, de modo que as diferenças ambientais e culturais de cada região convivam em diálogo e entendimento. Outra composição seria o trabalho em conjunto de universidades, instituições, Ministérios da Cultura, Educação, entidades de classe e bibliotecas escolares, visando fortalecer as pesquisas de campo sobre as competências, os perfis e as funções sociais dos bibliotecários.

Para que a biblioteca escolar realize-se plenamente como instituição educativa e social, a legislação (Lei 12.244, 24 de maio de 2010) deve ser cumprida. E, para tal realização, os bibliotecários precisam ser competentes no uso da Tecnologia da Informação e Comunicação para o ensino-aprendizagem. As competências, o perfil e a função social do bibliotecário, se amparadas por um direito efetivo, configuram uma rede atuante, onde as conexões se iluminam. A partir de então, colocam-se em prática ações para o entretenimento, a leitura, a informação e o conhecimento.

\section{REFERÊNCIAS}

ALMEIDA, Waldinéia Ribeiro; COSTA, Wilse Arena da Costa; PINHEIRO, Mariza Inês da Silva. Bibliotecários mirins e a mediação da leitura na biblioteca escolar. Revista ACB: Biblioteconomia em Santa Catarina, Florianópolis, v.17, n. 2, p. 472-490, 2012. Disponível em: <http://revista.acbsc.org.br/racb/article/view/812/pdf_1>. Acesso em: 10 jan. 2015.

ALMEIDA JÚNIOR, Oswaldo Francisco de; BORTOLIN, Sueli. Bibliotecário: um essencial mediador de leitura. In: SOUZA, R. J. (Org.). Biblioteca escolar e práticas educativas. Campinas: Mercado de Letras, 2009, p. 205-218.

\section{AMERICAN ASSOCIATION OF SCHOOL LIBRARIANS. Parâmetros para o aprendiz do século XXI. Chicago: AASL, 2007.}

ANTUNES, Walda de Andrade. Biblioteca escolar no Brasil: reconceituação e busca de sua identidade a partir de atores do processo ensino-aprendizagem. São Paulo, 1998. Tese (Doutorado) - Faculdade de Educação, Universidade de São Paulo, 1998.

ARENA, Dagoberto Buim. Leitura no espaço da biblioteca escolar. In: SOUZA, R. J. Biblioteca escolar e práticas educativas. Campinas: Mercado de Letras, 2009. p. 157-185.

BORGES, Jorge Luis. Obras completas. São Paulo: Ed. Globo, 1999. v. 3.

BRANDÃO, Mariane Braz. Contribuições e desafios na sociedade da informação para os profissionais que atuam em bibliotecas: estudo de caso da Biblioteca Maria Antonieta Franco de Siqueira. Ribeirão Preto, 2014. 102f. Monografia (Trabalho de Conclusão de 
Curso) - Curso de Ciências da Informação e da Documentação e Biblioteconomia, Faculdade de Filosofia, Ciências e Letras de Ribeirão Preto, Universidade de São Paulo, Ribeirão Preto.

CAMPELLO, Bernadete Santos. Perspectivas de letramento informacional no Brasil: práticas educativas de bibliotecários em escolas do ensino básico. Encontros Bibli (Online), Florianópolis, v.15, n.29, p. 184-208, 2010. Disponível em: <htpp://www.periodicos.ufsc.br/index.php/eb/article/view/1518-2924.2010v15n29p184>. Acessado em: 23 jan. 2015.

CASTRILLÓN, Silvia. EI derecho a leer y a escribir. México: Asolectura, 2004.

CASTRO FILHO, Cláudio Marcondes. O bibliotecário como profissional da informação: o mundo do trabalho, habilidades e competências. In: CASTRO FILHO, C.M. Olhares sobre a atuação do profissional da Ciência da Informação. São Paulo: Todas as Musas, 2013.

CASTRO FILHO, Cláudio Marcondes; CAMPOS, Larissa Bernardes. Fontes de informação em biblioteca escolar. São Paulo: Todas as Musas, 2014.

CASTRO FILHO, Cláudio Marcondes; PACAGNELLA, Juliana Nascimento. Biblioteca escolar pública, bibliotecário e ... In: CASTRO FILHO, C. M. e ROMÃO, L. M. S. (Org.). Dizeres sobre biblioteca escolar: palavras em movimento, Ribeirão Preto: Alphabeto, 2011. p. $97-108$.

CENDÓN, Beatriz Valadares. et al. Ciência da informação e biblioteconomia: novos conteúdos e espaços de atuação, Belo Horizonte: UFMG, 2005.

CUEVAS CERVERÓ, Aurora. La biblioteca escolar como centro de recursos para el aprendizaje (CRA). In: CERVERÓ, A. C. Lectura, alfabetización en información y biblioteca escolar. Gijón: Trea, 2007. p.163-188.

CUNHA, Miriam Vieira da; CRIVELLARI, Helena Maria Tarchi. O mundo do trabalho na sociedade do conhecimento e os paradoxos das profissões da informação. In: VALENTIM, M. L. P. Atuação do profissional na área de informação. São Paulo: Polis, 2004. p.39-54.

DUDZIAK, Elisabeth Adriana. A information literacy e o papel educacional das bibliotecas. 2007. 175 f. Dissertação (Mestrado em Ciência da Informação) - Escola de Comunicações e Artes, Universidade de São Paulo, São Paulo, 2007.

ELY, Neiva Helena. Dimensões da biblioteca escolar no ensino fundamental. Revista ACB, Santa Catarina, v. $8, \quad$ n. 1, 2003. p. 46-53. Disponível em: $<$ http://revista.acbsc.org.br/index.php/racb/article/view/405/510>. Acesso em: 10 maio, 2015.

FARIA, Sueli. et. al. Competências do profissional da informação: uma reflexão a partir da Classificação Brasileira de Ocupações. Ciência da Informação, Brasília, v. 34, n. 2, p. 2633, 2005.

FARIAS, Christianne Martins; CUNHA, Miriam Vieira da. O bibliotecário escolar e suas competências. Inf. \& Soc.: Est., João Pessoa, v. 19, n. 1, p. 29-35, jan./abr. 2009. 
FERRAREZI, L Ludmila. A biblioteca escolar nas teias do discurso eletrônico. Dissertação (Mestrado) - Faculdade de Filosofia, Ciências e Letras de Ribeirão Preto, Universidade de São Paulo, Ribeirão Preto, 2010.

FRAGOSO, Graça Maria. Biblioteca escolar - profissão e cidadania. Revista ACB: Biblioteconomia em Santa Catarina, Florianópolis, v.7, n.1/2, p. 240-250, 2002. <Disponível em: http://revista.acbsc.org.br/index.php/racb/article/view/381/463>. Acesso em: 12 jan. 2015.

FUENTES ROMERO, Juan José. La biblioteca escolar. Madrid: Arco/Libros, 2006.

FURTADO, Cassia. A biblioteca escolar brasileira no sistema educacional da sociedade da informação. In: SEMINÁRIO BIBLIOTECA ESCOLAR: ESPAÇO DE AÇÃO PEDAGÓGICA, 3., 2004, Belo Horizonte. Anais... Belo Horizonte: Escola de Biblioteconomia da Universidade Federal de Minas Gerais, 2004. Disponível em: <http://www.eci.ufmg.br/gebe/? Semin\%E1rios: III_Semin\%E1rio_Biblioteca_Escolar>. Acesso em: 21 jan. 2015.

GIL, António Carlos. Métodos e técnicas de pesquisa social. São Paulo: Atlas, 1999. INTERNATIONAL A. S. L. Declaração política da IASL sobre bibliotecas escolares. 1993. Disponível em: <http://www.oei.es/pdfs/rbe5.pdf>. Acesso em: 10 abr. 2015.

MARCONI, Marina de Andrade; LAKATOS, Eva Maria. Técnicas de pesquisa. São Paulo: Atlas, 2006.

MAROTO, Luciana Helena. Biblioteca escolar, eis a questão!: do espaço do castigo ao centro do fazer educativo. Belo Horizonte: Autêntica, 2012.

MARZAL, Miguel-Angel; CUEVAS CERVERÓ, Aurora. Biblioteca escolar para la sociedad del conocimiento en España. Ciência da Informação, v. 36, n.1, 2007. Disponível em: <http://revista.ibict.br/ciinf/index.php/ciinf/article/view/909/706>. Acesso em: 12 fev. 2015.

MILANESI, Luís. Biblioteca. Cotia: Ateliê Editorial, 2002.

MORAES, Fabiano; VALADARES, Eduardo. ; AMORIM, Marcela Mendonça. Alfabetizar letrando na biblioteca escolar. São Paulo: Cortez, 2013.

OLIVEIRA, Maria da Conceição Ferreira de. A função da biblioteca escolar. Cadernos do CED, v.4, n.10, 1987. p. 81-86.

PERRENOUD, Philippe. Desenvolver competências ou ensinar saberes? A escola que prepara a vida. Porto Alegre: Penso, 2013.

PERROTTI, Edmir. Biblioteca não é depósito de livros. Nova escola, n. 193, 2006. Disponível em: <http://revistaescola.abril.com.br/lingua-portuguesa/praticapedagogica/biblioteca-nao-deposito-livros-423601.shtml>. Acesso em: 9 abr. 2015. 
QUEIROZ, Solange Palhano. Information literacy: uma proposição expressiva para a biblioteca escolar. In: SILVA, R. J.; BORTOLIN, S. (Org.). Fazeres cotidianos na biblioteca escolar. São Paulo: Polis, 2006. p. 21-32.

RASTELI, Alessandro; CAVALCANTE, Lidia Eugênia. A Competência em informação e o bibliotecário mediador da leitura em biblioteca pública. Encontros Bibli: Revista Eletrônica de Biblioteconomia e Ciência da Informação, Florianópolis, v.18, n. 36, p. 157-180, 2013. Disponível em: <https://periodicos.ufsc.br/index.phb/eb/article/view/15182924.2013v18n36p157>. Acesso em: 24 jan. 2015.

RIGOLETO, Ana Paula Cardoso; DI GIORGI, Cristiano Amaral Garboggini. Outros parceiros na biblioteca escolar: democratização e incentivo à leitura. In: SOUZA, R. J. (Org.). Biblioteca escolar e práticas educativas. Campinas: Mercado de Letras, 2009. p. 219- 237.

SILVA, Lilian Lopes Martin; FERREIRA, Norma Sandra de Almeida; SCORSI, Rosalia de Angelo. Formar leitores: desafios da sala de aula e da biblioteca escolar. In: SOUZA, R. J. (Org.). Biblioteca escolar e práticas educativas. Campinas: Mercado de Letras, 2009. p. 4967.

SOUTO, S. M. O. O profissional da informação frente às tecnologias do novo milênio e às exigências do mundo do trabalho. Salvador: Cinform, 2003. Disponível em: <http://www.cinform-anteriores.ufba.br/iv_anais/frames.html>. Acesso em: 22 jan. 2015.

STUMPF, Ida Regina Chitto. Funções da biblioteca escolar. Cadernos do CED, v .4, n. 10, 1987 p. $67-80$.

TARGINO, Maria das Graças. Quem é o profissional da informação? Transinformação, Campinas, v. 12, n. 2, p. 61-69, 2000.

WALTER, Maria Tereza Machado Teles; BAPTISTA, Sofia Galvão. Formação profissional do bibliotecário. Encontros Bibli: Revista Eletrônica de Biblioteconomia e Ciência da Informação, Florianópolis, v. 13, n. 25, p. 84-103, 2008. 

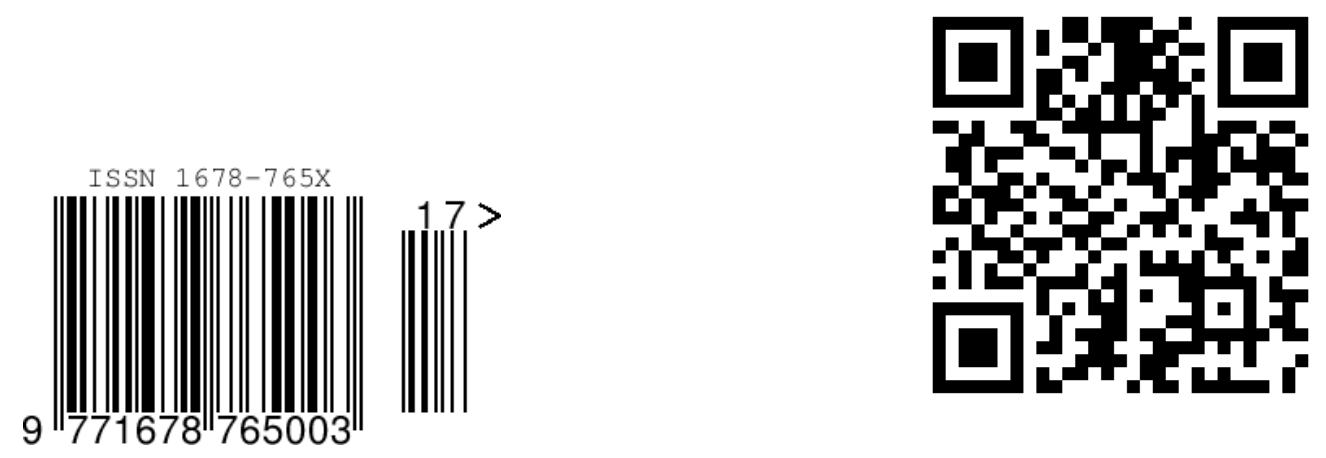